\title{
Binding and Internalization of Iron Oxide Nanoparticles Targeted To Nuclear Oncoprotein
}

\author{
Linda C. Knight ${ }^{1 *}$, Jan E. Romanoํ, Barbara Krynska², Scott Faro', Feroze B. Mohamed ${ }^{1}$ and Jennifer Gordon $^{3}$
}

${ }^{1}$ Radiology Department, Temple University School of Medicine, Broad and Ontario Streets, Philadelphia

${ }^{2}$ Neurology Department, Temple University School of Medicine, Broad and Ontario Streets, Philadelphia

${ }^{3}$ Neuroscience Department, Temple University School of Medicine, Broad and Ontario Streets, Philadelphia

\begin{abstract}
A targeted nanoconjugate is being developed for non-invasive detection of gene expression in cells expressing the $\mathrm{JC}$ virus oncoprotein, T-antigen, which has been associated with medulloblastoma and other cancers. JC virus T-antigen localizes predominantly to the nucleus via a classical monopartite nuclear localization signal (NLS). An antibody fragment which recognizes JC virus T-antigen was attached to cross-linked dextran coated iron oxide nanoparticles. Radiolabeled conjugates were added to mouse medulloblastoma cells expressing the target T-antigen to test their ability to bind to tumor cells and be internalized by the cells. All conjugates containing targeting antibody bound to cells and were internalized, with increasing levels over time. There was no difference in cell binding or internalization among conjugates containing 2, 4, 6 or 8 antibody fragments per nanoparticle. Conjugates with only nonspecific antibody on nanoparticles, or unconjugated nonspecific antibody, had significantly lower total binding and internalization than conjugates with targeting antibody. Unconjugated targeting antibody had equivalent or lower cell uptake compared with targeted nanoparticle conjugates. Specificity of uptake was demonstrated by $>80 \%$ reduction of nanoconjugate uptake in the presence of 100 fold excess of unconjugated antibody. The presence of a membrane translocation peptide (Tat) on the nanoparticles in addition to targeting antibody did not improve nanoconjugate internalization over the internalization caused by the antibody alone. This antibody nanoconjugate demonstrates feasibility of targeting a nuclear protein and suggests that a minimum number of antibody fragments per nanoparticle are sufficient for achieving binding specificity and efficient uptake into living cells.
\end{abstract}

Keywords: Nanoparticles; Antibodies; Monoclonal; Medulloblastoma; Magnetic Resonance Imaging; Neoplasms; Molecular Probes; Cell Line; Tumor; Ferrosoferric Oxide; Iodine Radioisotopes; Antigens; viral; tumor

Abbreviations: Ab: Targeting antibody; CLIO: Cross Linked Iron Oxide; DMEM: Dulbecco's Modified Eagle Medium; JCV: JC Virus; EDTA: Ethylene Diamine Tetraacetic Acid; HPLC: High Performance Liquid Chromatography; MH: Major Histocompatibility Complex; MION: Monocrystalline Iron Oxide Nanoparticle; MRI: Magnetic Resonance Imaging; NHS: N-Hydroxy Succinimide Ester; NLS: Nuclear Localization Signal; NP: Nano Particle; NSM: Nonspecific Mouse Antibody; PBS: Phosphate-Buffered Saline; PML: Progressive Multifocal Leukoencephalopathy; SMCC: Sulfosuccinimidyl-4-[Nmaleimidomethyl] Cyclohexane-1-Carboxylate; TAT: Membrane Translocation Peptide (Trans-Activating Transcriptional activator)

\section{Introduction}

Development of nanoparticles as agents for targeted detection of cancer cells through imaging has been an exciting area of investigation in recent years. Accurate targeting is of critical importance particularly when these agents are also used for shuttling therapeutic molecules to treat specific tumors or cancer. Magnetic resonance imaging (MRI) remains an attractive imaging platform due to its high spatial resolution. To improve sensitivity of MRI, several signal amplification strategies have been developed using targeted MR contrast agents coupled with biological markers. Strategies under development include those based on cellular internalization of superparamagnetic MR probes such as iron oxide nanoparticles[1].

The human polyomavirus, JC virus (JCV), is the causative agent of the demyelinating disease progressive multifocal leukoencephalopathy (PML), an increasingly common neurological complication in AIDS patients with approximately $8 \%$ of HIV- 1 positive individuals developing this progressive disease. Greater than $80 \%$ of the population is infected with the human polyomavirus, JC virus (JCV) during childhood, though in the majority of infected individuals the virus establishes latency in the kidney and does not induce any overt signs of disease[2]. In immunocompromised individuals such as AIDS patients, individuals on long term immunosuppressive therapies and individuals with lymphoproliferative disorders, however, reactivation of JCV results in the fatal demyelinating disease PML[2]. Over the last several years, studies have suggested a role for JCV in human cancer as a broad range of CNS tumors have been found to harbor JCV DNA sequences and to express the viral protein, $\mathrm{T}$-antigen, including medulloblastoma and other tumors of neural crest origin[3,4] (for a review, see Del Valle [5]. More recently, JCV has been detected in cancers of the gastrointestinal tract[6]. The viral regulatory protein, T-antigen, plays a critical role in the viral life cycle in that it directs viral early and late gene expression and viral DNA replication during lytic infection[7] In addition to its role in viral regulation during active replication, JCV T-antigen is considered an oncogene due to its demonstrated ability to transform cells in culture.

Cells expressing JCV T-antigen exhibit characteristics of

${ }^{*}$ Corresponding author: Linda C. Knight, PhD, Temple University Pharmacy Bldg Room B-49, 3307 N. Broad Street, Philadelphia, PA 19140, Tel: (215) 707-4940 Fax: (215) 707-8110,E-mail: LKnight@temple.edu

Received September 29, 2010; Accepted October 30, 2010; Published November 01, 2010

Citation: Knight LC, Romano JE, Krynska B, Faro S, Mohamed FB, et al. (2010) Binding and Internalization of Iron Oxide Nanoparticles Targeted To Nuclea Oncoprotein. J Mol Biomark Diagn 1:102. doi:10.4172/2155-9929.1000102

Copyright: @ 2010 Knight LC, et al. This is an open-access article distributed unde the terms of the Creative Commons Attribution License, which permits unrestricted use, distribution, and reproduction in any medium, provided the original author and source are credited. 
transformed or immortalized cells including morphological changes such as multinucleation, rapid doubling time, growth in anchorage independence and subcutaneous growth in the Nude mouse. JCV T-antigen maintains helicase, $\alpha$-polymerase, ATPase and DNA binding activities[7] as well as exhibiting the ability to physically interact with the tumor suppressor protein, p53 and the retinoblastoma protein family members, pRb, p130 and p107 [8-11]. It is through binding that $\mathrm{T}$-antigen is thought to sequester and inactivate p53 and pRb, subsequently affecting normal cell cycle regulatory controls. Similar to the well known SV40 T-antigen, JCV T-antigen specifically localizes to the nuclear compartment of infected and transformed cells due to the presence of a classical monopartite nuclear localization signal (PKKKKKV)[7,12]. While T-antigen exerts its oncogenic effect through localization to the nucleus, T-antigen has also been detected in the cell cytoplasm. In addition, it is well established that the T-antigen of the prototypical polyomavirus, SV40, is processed and presented on the surface of infected and transformed cells where it can be targeted by cytotoxic T-lymphocytes. Thus, it is hypothesized that T-antigen provides a suitable target for the nanoparticle based strategy described in the current study.

We sought to develop a targeted nanoconjugate for non-invasive detection of gene expression in cancer cells expressing the JC virus oncoprotein, T-antigen. In this study, an antibody fragment which recognizes JC virus $\mathrm{T}$-Antigen was used for targeting iron oxide nanoparticles to tumor cells. Targeting of individual cancer cells presents a challenge for in vivo imaging, because a sufficiently high concentration of the contrast agent must be delivered to the tissue and the protein on the cell surface may be limited in concentration or saturable. Endocytosis of the contrast agent is desirable so that the agent could accumulate inside the cell and achieve a higher contrast effect. In this manner, the nanoparticle described here is designed to targeted peptides of the T-antigen protein which are displayed on the cell surface by MHC I molecules, which will then be internalized in order to retain and concentrate the contrast agent. In addition to the antibody targeting approach, peptide sequences such as a region of the HIV-1 Tat protein known to be responsible for nuclear import (Tat peptide) may also be coupled to the nanoparticle in order to enhance uptake. Tat alone (without targeting antibody) coupled to nanoparticles has been used by others [13-15]. Ultimately, such a particle could be used to enable MR imaging of T-antigen expression, by using the contrast enhancement provided by the superparamagnetic iron oxide core of the nanoconjugates. In this study, a radiolabel was used to quantify the binding and internalization of nanoconjugates by cells in vitro. The required number of antibody fragments per nanoconjugate was tested. Studies also tested whether there is a need for an additional membrane translocation peptide to achieve cell internalization.

\section{Materials and Methods}

\section{Preparation of nanoparticle conjugates bearing T-antigen specific antibody or control antibody}

Dextran-coated monocrystalline iron oxide nanoparticles (MION47) were purchased from Center for Molecular Imaging Research, Massachusetts General Hospital. The particles (360 nmol particles, $20 \mathrm{mg}$ Fe in $1.72 \mathrm{~mL}$ ) were made basic by the addition of $2.9 \mathrm{~mL}$ of $5 \mathrm{M} \mathrm{NaOH}$ and treated with $3.44 \mathrm{~mL}$ epichlorohydrin for 8 hours with stirring to crosslink the dextran coat for stability to make CrossLinked Iron Oxide (CLIO). In order to produce amine groups on each dextran strand (CLIO- $\mathrm{NH}_{2}$ ), $5.16 \mathrm{~mL} \mathrm{30 \%}$ ammonium hydroxide was added, followed by vigorous stirring for 10 hours at room temperature [16].
The CLIO- $\mathrm{NH}_{2}$ particles were purified, buffer-exchanged into $5 \mathrm{mM}$ citrate, $\mathrm{pH} 8$ and concentrated to $21 \mathrm{mg} / \mathrm{mL}$ using an Amicon Ultra 4 centrifugal concentrator with molecular weight cutoff of 30,000 (Millipore, Billerica, MA). The final concentration of CLIO- $\mathrm{NH}_{2}$ was determined by a spectrophotometric method after dissolving a sample of particles in hydrochloric acid with hydrogen peroxide[17].

Mouse monoclonal antibody pAb416 (EMD Biosciences, La Jolla, CA) which recognizes JC virus T-antigen was coupled to iron oxide nanoparticles (NPs) in order to achieve targeting to T-antigen expressing tumor cells. For control studies, a nonspecific mouse immunoglobulin G (NSM; Thermo Fisher) was coupled in place of targeting antibody.

For some studies, both Ab and NSM were attached to nanoparticles in various ratios to test the effect of number of $\mathrm{Ab}$ fragments per NP while keeping the total number of fragments/NP the same. To permit quantification of coupling and cell binding, antibodies were tagged with fluorophores or radiolabels prior to coupling to nanoparticles. Prior to tagging, antibody pAb416 was concentrated to $1-4 \mathrm{mg} / \mathrm{mL}$ in a MicroCon YM-30 centrifugal concentrator (Millipore, Billerica, MA). Control antibody NSM was used as received $(5.6 \mathrm{mg} / \mathrm{mL}$ in PBS, $\mathrm{pH}$ 7.6).

Antibodies were radiolabeled with ${ }^{125}$ I using the Iodogen method[18]. Briefly, to $50 \mathrm{ug}$ antibody in $35 \mathrm{uL}$ PBS was added 50 ul of $0.18 \mathrm{M}$ sodium phosphate, $0.15 \mathrm{M}$ sodium chloride, $\mathrm{pH} 7.6$ and $565 \mathrm{uCi}$ of no-carrier-added ${ }^{125} \mathrm{I}$ (Perkin Elmer, N. Billerica, MA). This mixture was transferred to a septum-capped microfuge tube coated at the bottom with 20 ug of Iodogen (1,3,4,6-tetrachloro-3 $\alpha, 6 \alpha$ diphenyl glycoluril; Pierce Thermo Fisher, Rockford, IL). After 15 minutes at room temperature, the antibody solution was removed from the reaction vial and purified by size-exclusion chromatography (MicroBioSpin 6, pre-equilibrated with PBS pH 7.2, containing $0.2 \%$ gelatin) to remove free iodide. Radiolabeled antibodies were stored at $4^{\circ} \mathrm{C}$ until use.

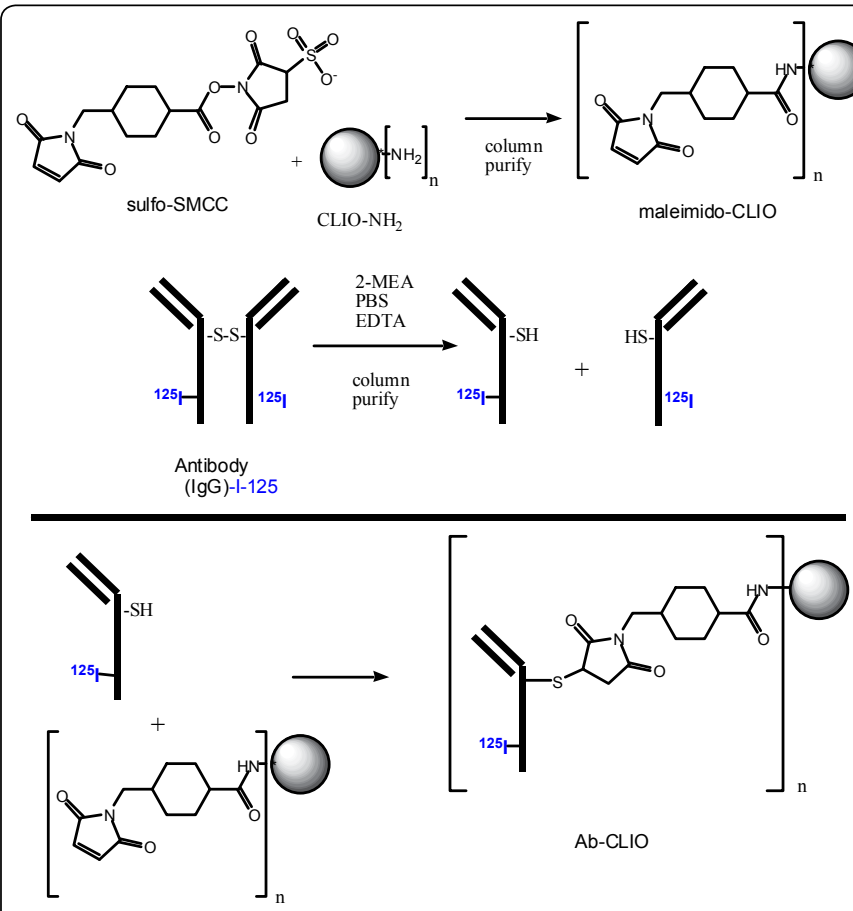

Figure 1: Scheme for coupling ${ }^{125}$-labeled antibody to CLIO nanoparticles. 
The method of coupling antibodies to nanoparticles is outlined in Figure 1. In order to accomplish the covalent coupling of antibodies to nanoparticles, $90 \mathrm{pmol}$ aminated nanoparticles (CLIO-NH $\mathrm{NH}_{2}, 10.4 \mathrm{ug}$ $\mathrm{Fe}$ ) in 10 ul of $25 \mathrm{mM}$ sodium citrate buffer $\mathrm{pH} 8.0$ was diluted with $10 \mathrm{ul}$ of $0.1 \mathrm{M}$ phosphate buffer, $\mathrm{pH} 7.4$ and reacted with $4 \mathrm{ul}(9 \mathrm{nmol})$ sulfo-SMCC (sulfosuccinimidyl-4-[N-maleimidomethyl] cyclohexane1-carboxylate; Thermo Fisher Scientific, Rockford, IL) dissolved immediately before use to $1 \mathrm{mg} / \mathrm{mL}$ in MilliQ water. This was allowed to react at room temperature for 2 hours to covalently attach maleimide functional groups to amino groups on nanoparticles, providing spacer arms of about $8.3 \AA$. The maleimido-NPs were purified on a MicroBioSpin 6 column (Bio-Rad, Hercules, CA) preequilibrated with PBS pH 7.0. Concurrently, the antibody (188 pmol in $36 \mathrm{ul} \mathrm{PBS} \mathrm{pH}$ 7.2) was reacted with $3.6 \mathrm{uL}$ 2-mercaptoethylamine (2-MEA) solution $(60 \mathrm{mg} / \mathrm{ml})$ to cleave the immunoglobulin disulfides selectively in the hinge region to separate the antibody into two monovalent halves. This reaction was heated at $37^{\circ} \mathrm{C}$ for 90 minutes in a heat block, then purified on a desalting column (MicroBioSpin 6), pre-equilibrated with PBS pH 6.5, 1 mM EDTA. The free sulfhydryls in the antibody fragments were then coupled to the maleimide groups on NPs, forming thioether linkages. From the maleimido-NP preparation and the reduced antibody preparations, five separate coupling reactions were set up in order to couple T-antigen specific antibody and nonspecific antibody to the nanoparticles in various ratios. In separate microfuge tubes, required volumes of each reduced antibody (pAb416 or NSM) were mixed together and then maleimido-NP was added. In each reaction, there was 15 pmol of maleimido-NPs reacting with a total of 150 pmol of antibody (as half-IgG molecules), in ratios of 10:0:1, 7.5:2.5:1, 5:5:1, 2.5:7.5:1 and 0:10:1 pAb416: NSM:NP. The reactions were allowed to proceed overnight at $4^{\circ} \mathrm{C}$, after which the nanoparticles were separated from unbound antibodies using MicroSpin S-300 HR size-exclusion spin columns (GE Healthcare, Piscataway, NJ). The number of antibody fragments actually coupled to the nanoparticles was determined by comparing the concentration of separated unbound antibody to starting antibody by UV absorbance and radioactive counts. Sizeexclusion HPLC with a BioSilect 400-S column (Bio-Rad, Hercules, CA) eluted with PBS pH 6.8, was used to separate antibody from gelatin in order to determine the amount of pAb416 antibody that had bound to the NPs. The concentration of nanoparticles was determined by iron assay[17] with the assumption that each nanoparticle core has 2064 atoms of iron[19]. The concentration of antibody fragments was divided by the concentration of nanoparticles to obtain the number antibody fragments per nanoparticle[20].

\section{Cell binding studies using radiolabeled antibody conjugates}

Cells of BSB8 mouse medulloblastoma cell line which expresses JCV T-Antigen [10] were grown at $37^{\circ} \mathrm{C}$ in $0.7 \% \mathrm{CO}_{2}$ in DMEM supplemented with $10 \%$ fetal bovine serum and antibiotics. Cells were seeded at a concentration of $10^{5}$ cells per well in 24-well tissue culture plates. Cells were incubated in fresh media containing ${ }^{125}$ I-antibody conjugates at a final concentration of $1 \mathrm{nM}$. Nanoparticle conjugates carried a total of 8 labeled antibody fragments, of which $8,6,4,2$ or none (control) were targeting antibody pAb416 fragments. Unconjugated ${ }^{125}$ I-pAb416 (positive control) and ${ }^{125}$ I-NSM (negative control) were also tested at the same concentration as the NP-bound antibody. After incubation at $37^{\circ} \mathrm{C}$ for $1,2,6$ or 24 hours, unbound conjugates were aspirated and cells were washed with $1 \mathrm{X}$ PBS. Surface-bound conjugate was determined by treatment with $0.5 \mathrm{M} \mathrm{NaCl}, 0.2 \mathrm{M}$ acetic acid on ice for 5 minutes, after which the supernatant was aspirated and cells were washed with PBS. Finally, the washed cells were removed from the wells by treatment with $0.05 \%$ trypsin/ $0.5 \mathrm{mM}$ EDTA and were collected. Unbound, surfacebound and internalized conjugates were counted separately for ${ }^{125}$ I content in an automatic gamma counter (Wizard 1480, Perkin-Elmer). The following were calculated:

$$
\begin{aligned}
& \text { Internalized }=\frac{\text { Residual counts in cells }}{\text { Total of all fractions }} \\
& \text { Total bound }=\frac{\text { Surface bound }+ \text { residual counts in cells }}{\text { Total of all fractions }}
\end{aligned}
$$

Each condition was performed in triplicate and the results were averaged. The experiment was repeated on four different occasions to verify reproducibility. Results were expressed as total antibody molecules bound per cell and number of antibody molecules internalized per cell, based on an estimated $2 \times 10^{5}$ cells per well at the time the conjugates were added. The binding and internalization of ${ }^{125} \mathrm{I}$-pAb416 IgG or ${ }^{125} \mathrm{I}-\mathrm{NSM} \operatorname{IgG}$ was calculated the same way.

The specificity of uptake was tested by adding a 100-fold excess of unconjugated pAb416 to one well, prior to adding ${ }^{125} \mathrm{I}-\mathrm{pAb} 416$ NPs containing 6 or 8 pAb416 fragments per nanoparticle. After incubation for 1 hour, the cells were processed as described above. The results were compared with the results from a 1 hour incubation with ${ }^{125} \mathrm{I}-\mathrm{pAb} 416-\mathrm{NPs}$ alone.

\section{Preparation of nanoconjugates containing targeting antibody and membrane-translocating peptide}

In order to test the effect of a membrane translocation peptide on the binding and cell internalization of the nanoparticles, a region of HIV-1 Tat responsible for internalization of the protein (Tat peptide) was attached to NP. The peptide Gly-Arg-Lys-Lys-Arg-Arg-Gln-Arg-ArgArg-Gly-Tyr-Lys (fluorescein)-Cys ("Fl-Tat") was custom synthesized (BioPeptide Co, San Diego, CA). CLIO-NH $\mathrm{N}_{2}$ was reacted with sulfoSMCC as described above to prepare NP-maleimide. Different ratios of reduced $\mathrm{Ab}$ fragments (labeled with ${ }^{125} \mathrm{I}$ ) and Fl-Tat were added together to $15 \mathrm{pmol} \mathrm{NP}$-maleimide. The ratios of reactants were $2.5: 0: 1,2.5: 2.5: 1$ and $2.5: 7.5: 1$ antibody :Tat :NP. After reacting overnight at $4^{\circ} \mathrm{C}$, unbound antibody and peptide were separated from nanoparticles by MicroSpin S300HR size-exclusion spin columns. The unbound material was eluted from the spin columns and quantified. The amount of unbound antibody was determined by radioactive counts and the amount of unbound Tat peptide was determined by its fluorescein tag (absorbance at $494 \mathrm{~nm}$ ). These were subtracted from the total antibody and Tat peptide originally added to determine the amount that had bound to the nanoparticles. The resulting conjugates with various levels of $\mathrm{Ab}$ and Tat peptide were tested for internalization by T-antigen positive cells.

The ${ }^{125}$-labeled conjugates containing both antibody and Tat peptide were added at a concentration of $2 \mathrm{nM}$ antibody to wells in which $1 \times 10^{4} \mathrm{~T}$-antigen positive cells had been growing for 48 hours. The conjugates were incubated with the cells for 24 hours, then the cells were processed to separate unbound and surfacebound conjugates from internalized conjugates as above. These studies were performed in quadruplicate. Results were expressed as total nanoparticles bound per cell and number of nanoparticles internalized per cell, based on an estimated $2 \times 10^{4}$ cells per well at the time the conjugates were added.

\section{Statistical analysis}

Results are expressed as mean \pm 1 standard deviation and were 
analyzed by Students t-test (2-tailed). A value of $\mathrm{p}<0.05$ was used to reject the null hypothesis.

\section{Results}

\section{Number of antibodies per nanoparticle conjugate}

In order to determine the effect of increasing numbers of targeting antibody molecules per nanoparticle, nanoparticles were formulated to contain 2, 4, 6, or 8 T-antigen specific antibody fragments out of a total of 8 antibody fragments per particle. The number of antibody fragments coupled to the nanoparticles was determined by comparing the concentration of separated unbound antibody to starting antibody. Using the scheme shown in Figure 1 and under the reaction conditions used, $80 \%$ of added antibody consistently bound to nanoparticles. The number of antibody fragments per particle was a total of 8 , with the difference made up with NSM, as shown in Figure 2.

\section{Cell binding studies using radiolabeled antibody conjugates}

Nanoparticles with increasing amounts of anti-T-antigen antibody fragments were incubated with T-antigen positive medulloblastoma cells for up to $24 \mathrm{~h}$. After incubation, the amounts of unbound antibody remaining in the culture media, antibody bound to the cell surface and antibody taken up by the T-antigen positive tumor cells were calcuated. All conjugates containing T-antigen targeting antibody bound to cells, with increasing levels over time (Figure 3a). Maximal binding had still not been reached by 24 hours of incubation. During the incubation, up to $50 \%$ of bound counts were internalized by 24 hours (Figure 3b). There was no difference in cell binding or internalization between conjugates containing $2,4,6$, or $8 \mathrm{Ab}$ fragments per NP. Conjugates with only ${ }^{125} \mathrm{I}$-NSM antibody on NP, or unconjugated ${ }^{125}$ I-NSM antibody, had significantly lower binding and internalization than conjugates with ${ }^{125} \mathrm{I}$-anti-T-antigen $(\mathrm{p}<0.0003, \mathrm{p}<0.003$ vs. $8 \mathrm{Ab}$ frags/NP; $\mathrm{p}<0.0003, \mathrm{p}<0.002$ vs. $2 \mathrm{Ab}$ frags/NP, at $24 \mathrm{hr}$ ) demonstrating the specificity of the nanoparticle for the $\mathrm{T}$-antigen expressing cells. Unconjugated ${ }^{125} \mathrm{I}$-anti-T-antigen antibody had slightly lower cell uptake compared with targeted NP conjugates ( $p<0.02$ vs. $8 \mathrm{Ab} / \mathrm{NP}$ or $2 \mathrm{Ab} / \mathrm{NP}$, at $24 \mathrm{hr}$ ) suggesting that the nanoparticle enhanced the ability of conjugated antibody to bind to the cell surface. The trends for cell surface binding (Panel A) and internalization (Panel B) were similar.

To further demonstrate specificity of the T-antigen targeting nanoparticle, pre-incubation of the cells in the presence of 100 -fold excess unconjugated anti-T-antigen antibody prior to incubation with anti-T-antigen-NP. After incubation for $1 \mathrm{~h}$, binding and internalization of ${ }^{125}$ I-anti-T-antigen-NP was found to be reduced by $>80 \%$ (Figure 4 ).

\section{Binding and internalization of NPs containing antibody and Tat peptide}

In order to determine whether a peptide encoding a Tat internalization sequence could facilitate uptake of the nanoparticle, nanoconjugates with various levels of ${ }^{125} \mathrm{I}-\mathrm{Ab}$ and Tat peptide were prepared and tested for uptake by T-antigen positive cells. The purified conjugates had the following average levels of antibody and Tat peptide per NP: 2:0, 2:2 and 2:6 Ab fragment: Tat peptide. After incubation with $\mathrm{T}$-antigen positive cells for 24 hours, the cells were processed to separate unbound and surface-bound conjugates from internalized nanoparticles. As shown in Figure 5, at a level of $2 \mathrm{Ab}$ fragments per nanoparticle, the presence of Tat peptide provides at most a slight enhancement of cell internalization $(\mathrm{p}<0.005)$ (Figure

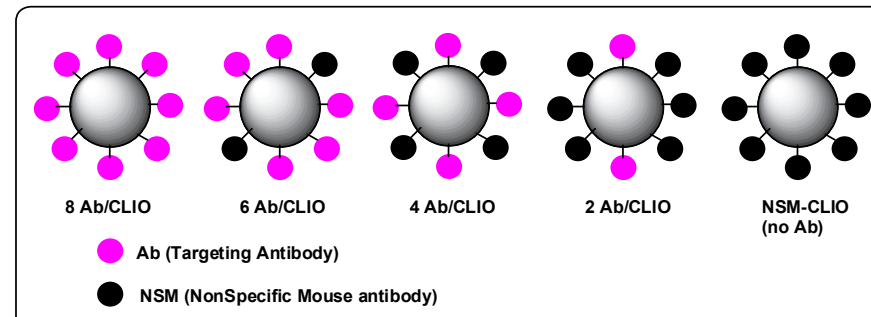

Figure 2: Antibody-nanoconjugates prepared. Different number of targeting antibodies and nonspecific control antibodies were coupled to each particle so that the total number was 8 per nanoparticle.

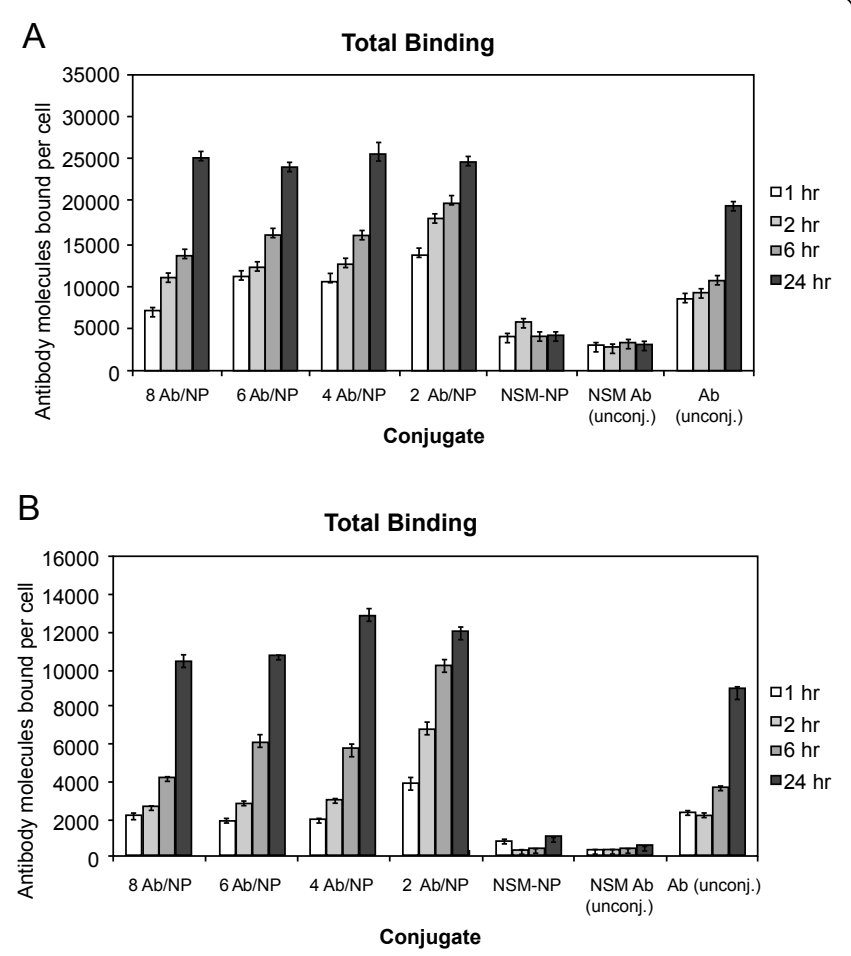

Figure 3: Binding of conjugates to T-Antigen positive cells. Effect of conjugate composition and time. A. Total Binding of Conjugates. B. Internalization of Conjugates. $\mathrm{Ab}=\mathrm{pAb} 416$ anti-T-Antigen antibody. $\mathrm{NSM}=$ nonspecific mouse antibody. All conjugates were labeled with ${ }^{125}$.

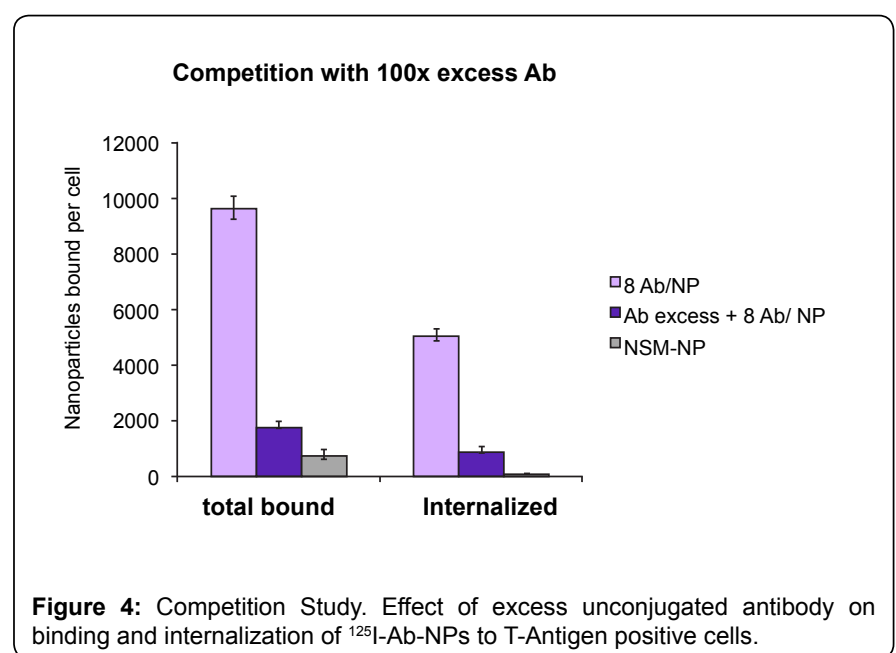



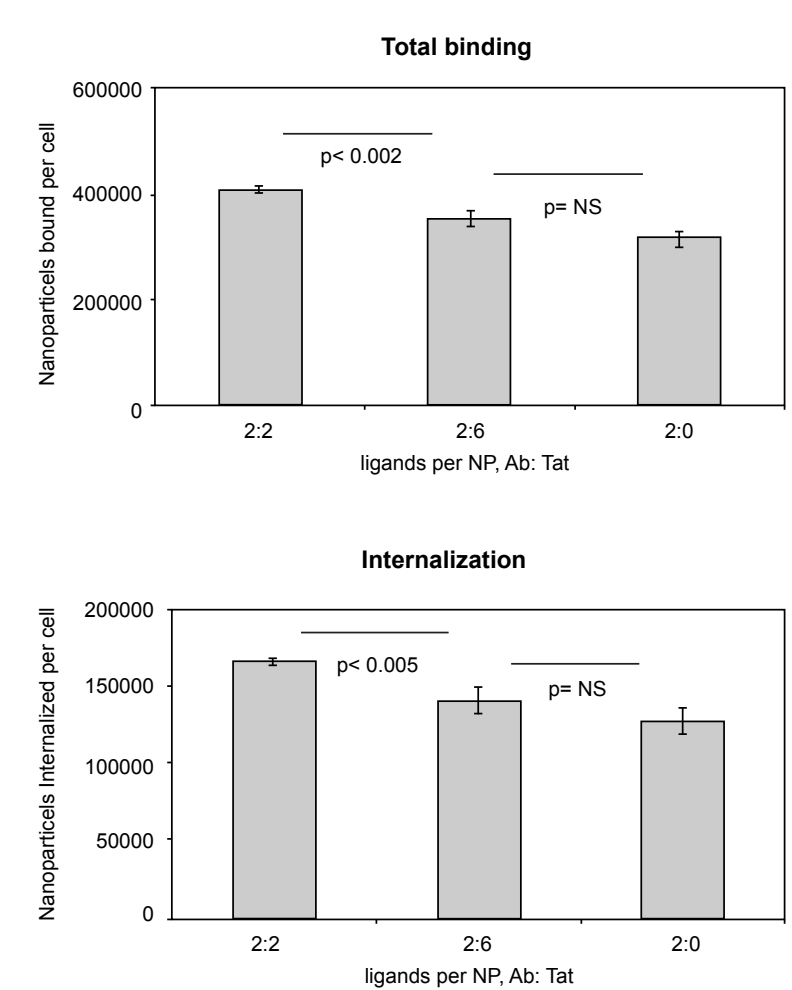

Figure 5: Effect of Tat peptide on binding to and internalization by T-Antigen positive cells. A. Total binding. B. Internalization. Nanoconjugates were composed of pAb416 antibody fragments and Tat peptides bound to the surface in 2:2:1, 2:6:1 or $2: 0: 1$ ratios of antibody:Tat:NP.

$5 b)$. Decreasing the relative number of $\mathrm{Ab}$ fragments to Tat peptides (2 $\mathrm{Ab}: 6 \mathrm{Tat} / \mathrm{NP})$ did not increase the internalization of the NPs compared to $2 \mathrm{Ab}: 2$ Tat or $2 \mathrm{Ab}: 0$ Tat. It appears that the $\mathrm{Ab}$ fragments alone are capable of inducing internalization and that the addition of Tat did not appreciably affect uptake.

\section{Discussion}

We constructed nanoconjugates to specifically target JCV T-antigen expressing cancer cells. The ultimate goal is a multimodal nanoconjugate which can target cells, provide diagnostic images and perhaps deliver therapeutics.

The iron oxide nanoparticle synthesized and conjugated in this work $\left(\mathrm{CLIO}-\mathrm{NH}_{2}\right)$ is a well-characterized superparamagnetic MRI contrast agent [21]. The MR relaxation properties (R2 and R2* shortening effects) of the CLIO- $\mathrm{NH}_{2}$ particle can be exploited to generate unique MR contrast characteristics. Conjugated CLIO- $\mathrm{NH}_{2}$ particles can then be used to generate diagnostic images pertaining to specific binding sites of the target cells.

The nanoconjugates consisted of a core of crosslinked dextrancoated iron oxide to which was coupled antibodies (anti-T-antigen and nonspecific) and peptide (Tat membrane translocation peptide). The present project was limited to in vitro studies in cultured cells to demonstrate the specific targeting and internalization of the nanoconjugate. An antibody fragment $(\mathrm{Ab})$ which recognizes JC virus $\mathrm{T}$-antigen was coupled to the CLIO- $\mathrm{NH}_{2}$ in order to achieve targeting of iron oxide nanoparticles to tumor cells. Several antibodies were initially screened and the one with the best binding to T-antigen positive cells was chosen for these studies.

It is well-known that in T-antigen-positive cells, T-antigen is primarily present in the nucleus and the presence of nuclear $\mathrm{T}$-antigen in the BSB8 medulloblastoma cells has been previously described[10]. In order for nanoconjugates to be targeted to T-antigen-positive cells, the antigen also needs to be present on the surface of the cell membrane. In addition, the detection of the highly homologous SV40 T-antigen within the cell membrane has also been described previously by others[22,23] (for review, see Butel et al[24]). The present studies suggest that there is some T-antigen present on the cell surface and that antibody-antigen binding results in internalization of antibodyNP conjugates.

The targeting antibody used in these studies was provided by the manufacturer as a dilute solution $(0.2 \mathrm{mg} / \mathrm{mL})$ containing $0.2 \%$ gelatin. Attempts to remove gelatin without loss of antibody was not successful (data not shown). The presence of gelatin was found to be important for recovery of antibody from centrifugal size exclusion columns used in purification steps. Thus, there was gelatin in the antibody preparation during the coupling to nanoparticles and a procedure needed to be chosen that would selectively couple antibody to nanoparticles without coupling gelatin. Because gelatin protein does not contain cysteine $[25,26]$, an approach that involved partial reduction of IgG to generate sulfhydryl groups was chosen as an antibody-selective method for coupling. Treatment of antibody with 2-mercaptoethylamine is commonly used to selectively reduce disulfides in the hinge region of $\operatorname{lgG}$. Attachment of the antibodies by the thiol group in the hinge region assured that the attachment would not interfere with the antigen binding site[27]. For stability, the method involving coupling of maleimide groups to sulfhydryl groups to form a thioether bond was chosen.

The nanoparticles used in this investigation are small, with a core of iron oxide $4.6 \mathrm{~nm}$ in diameter and a coating of $25 \pm 6$ dextran chains of $10 \mathrm{kDa}$ each for an effective diameter of about $20 \mathrm{~nm}[19]$. Theoretically, an antibody fragment could be coupled to the amine end of each of the 25 chains. However, we observed that when we coupled more than 8 antibody fragments per nanoparticle, the particles tended to aggregate and settle out of solution. Thus, we did not perform binding studies with more than 8 antibody fragments per nanoparticle.

There was no difference between $2,4,6$, or $8 \mathrm{Ab}$ fragments per nanoparticle in the level of binding and internalization. Thus, only $2 \mathrm{Ab}$ fragments per CLIO are needed for targeting. The presence of a large excess of unconjugated pAb416 reduced the binding and internalization of ${ }^{125} \mathrm{I}$-anti-T-antigen-NP by $>80 \%$, suggesting that the observed cell binding is due to a specific interaction between antigen and antibody which can be affected by competition.

Conjugates with Tat peptide in addition to targeting antibody were prepared to enhance the internalization of the conjugates by the cells. The coupling of Tat peptides alone to the nanoparticles (without targeting antibody) cause nonspecific internalization by both T-Antigen positive and negative cells (data not shown). This has been well-established by others [13-15]. There was concern that the presence of Tat peptides on antibody-NP conjugates might induce nonspecific uptake into cells. However, in the T-antigen positive cells, the presence of up to 6 Tat peptides per nanoparticle did not increase uptake over what was observed with 2 antibody fragments per nanoparticle. In a separate experiment, a fluorescenttagged conjugate that contained both targeting antibody and Tat 
Citation: Knight LC, Romano JE, Krynska B, Faro S, Mohamed FB, et al. (2010) Binding and Internalization of Iron Oxide Nanoparticles Targeted To Nuclear Oncoprotein. J Mol Biomark Diagn 1:102. doi:10.4172/2155-9929.1000102

Page 6 of 6

membrane translocation peptide (with an average of $6.3 \mathrm{Ab}$ and 7.2 Tat per CLIO) bound to T-Antigen positive cells at 2 and 24 hours (not shown). Uptake of the conjugate by T-Antigen negative cells was very slight, despite concerns that the Tat peptide might cause nonspecific internalization. Nanoparticles without targeting antibody or Tat did not bind to or enter cells (not shown). Nonspecific antibody (alone or bound to NPs) did not bind to cells. The presence of the Tat peptide together with $\mathrm{Ab}$ on the conjugate does not appear to provide an advantage over the use of the $\mathrm{Ab}$ fragment alone, as the $\mathrm{Ab}-\mathrm{NP}$ without Tat was shown to be internalized by the cells. Further studies will be needed to elucidate the intracellular location of the internalized conjugates.

\section{Conclusions}

Two antibody fragments per nanoconjugate appear to be sufficient for cell targeting. Conjugates with targeting antibody bind to and are internalized into nuclear antigen-expressing cells. It was concluded that the presence of the Tat peptide together with $\mathrm{Ab}$ on the conjugate does not appear to provide an advantage over use of the Ab fragment alone. This antibody-NP conjugate is promising for further study.

\section{Acknowledgments}

This work was supported by the Commonwealth of Pennsylvania under the Ben Franklin Technology Development Authority and the Nanotechnology Institute by the Department of Health of the Commonwealth of Pennsylvania and by National Institutes of Health grant R21CA137747.

\section{References}

1. Weissleder R (1999) Molecular imaging: exploring the next frontier. Radiology 212: 609-614

2. Berger JR, Concha M (1995) Progressive multifocal leukoencelphalopathy: Evolution of a disease once considered rare. J Neurovirol 1: 5-18.

3. Del Valle L, Gordon J, Assimakopoulou M, Enam S, Geddes JF, et al. (2001) Detection of JC Virus DNA sequences and expression of the viral regulatory protein T-antigen in tumors of the central nervous system. Cancer Res 61: 4287-4293.

4. Krynska B, Otte J, Franks R, Khalili K, Croul S (1999) Human ubiquitous $\mathrm{JCV}(\mathrm{CY})$ T-antigen gene induces brain tumors in experimental animals. Oncogene 18: 39-46.

5. Del Valle L, Gordon J, Ferrante P, Khalili K (2001) JC virus in experimental and clinical brain tumorigenesis. In: Khalili K, Stoner GL, editors. Human polyomaviruses: Molecular and clinical perspectives Wiley Liss, New York, NY. pp. $409-430$.

6. Del Valle L, White MK, Enam S, Piña Oviedo S, Bromer MQ, et al. (2005) Detection of JC virus DNA sequences and expression of viral $T$ antigen and agnoprotein in esophageal carcinoma. Cancer 103: 516-527.

7. Frisque RJ, White FA III (1992) The molecular biology of JCV, causative agent of progressive multifocal leukoencephalopathy. In: Molecular Neurovirology RP Roos (ed) Humana Press, Totowa, NJ : 25-128.

8. Bollag B, Chuke WF, Frisque RJ (1989) Hybrid genomes of the polyomaviruses $\mathrm{JC}$ virus, BK virus, and simian virus 40: identification of sequences important for efficient transformation. J Virol 63: 863-872.
9. Dyson N, Bernards R, Friend SH, Gooding LR, Hassel JA, et al. (1990) Large $T$ antigens of many polyoma viruses are able to form complexes with the retinoblastoma protein. J Virol 64: 1353-1356

10. Krynska B, Del Valle L, Gordon J, Otte J, Croul S, et al. (2000) Identification of a novel p53 mutation in JCV-induced mouse medulloblastoma. Virology 274 65-74.

11. Ludlow JW, Skuse GR (1995) Viral oncoprotein binding to pRb, p107, p130 and p300. Virus Res 35: 113-121.

12. Macara IG (2001) Transport into and out of the nucleus. Microbiol Mol Biol Rev 65: $570-594$

13. Josephson L, Tung CH, Moore A, Weissleder R (1999) High-efficiency intracellular magnetic labeling with novel superparamagnetic-Tat peptide conjugates. Bioconjug Chem 10: 186-191.

14. Lewin M, Carlesso N, Tung CH, Tang XW, Cory D, et al. (2000) Tat peptidederivatized magnetic nanoparticles allow in vivo tracking and recovery of progenitor cells. Nat Biotechnol 18: 410-414.

15. Wunderbaldinger $P$, Josephson L, Weissleder $R$ (2002) Tat peptide directs enhanced clearance and hepatic permeability of magnetic nanoparticles. Bioconjug Chem 13: 264-268.

16. Pittet MJ, Swirski FK, Reynolds F, Josephson L, Weissleder R (2006) Labeling of immune cells for in vivo imaging using magnetofluorescent nanoparticles. Nat Protoc 1: 73-79.

17. Moore A, Josephson L, Bhorade RM, Basilion JP, Weissleder R (2001) Human transferrin receptor gene as a marker gene for MR imaging. Radiology 221 244-250.

18. Fraker PJ, Speck JC Jr (1978) Protein and cell membrane iodinations with a sparingly soluble chloroamide, 1,3,4,6-tetrachloro-3a, 6a-diphenylglycoluril. Biochem Biophys Res Commun 80: 849-857.

19. Shen T, Weissleder R, Papisov M, Bogdanov AJ, Brady TJ (1993) Monocrystalline iron oxide nanocompounds (MION): physicochemical properties. Magn Reson Med 13: 599-604.

20. Högemann D, Josephson L, Weissleder R, Basilion JP (2000) Improvement of MRI probes to allow efficient detection of gene expression. Bioconjug Chem 11: $941-946$

21. Wunderbaldinger $P$, Josephson $L$, Weissleder $R$ (2002) Crosslinked iron oxides (CLIO):a new platform for the development of targeted MR contrast agents. Acad Radiol Suppl 2: S304-S306.

22. Henning R, Lange-Mutschler J (1983) Tightly associated lipids may ancho SV40 large T antigen in plasma membrane. Nature 305: 736-738.

23. Santos M, Butel JS (1984) Antigenic structure of simian virus 40 large tumo antigen and association with cellular protein p53 on the surfaces of simian virus 40-infected and -transformed cells. J Virol 51: 376-383.

24. Butel JS, Jarvis DL, Maxwell SA (1989) SV40 T-antigen as a dual oncogene: Structure and function of the plasma membrane-associated population. Ann N Y Acad Sci 567: 104-121.

25. Eastoe JE (1955) The amino acid composition of mammalian collagen and gelatin. Biochem J 61: 589-600.

26. Eastoe JE (1957) The amino acid composition of fish collagen and gelatin Biochem J 65: 363-368.

27. Shahinian S, Silvius JR (1995) A novel strategy affords high-yield coupling of antibody Fab' fragments to liposomes. Biochim Biophys Acta 1239: 157-167. 